\title{
Paradoxic Activation of the Renin-Angiotensin System in Twin-Twin Transfusion Syndrome: An Explanation for Cardiovascular Disturbances in the Recipient
}

\author{
DOMINIQUE MAHIEU-CAPUTO, ALAIN MEULEMANS, JELENA MARTINOVIC, \\ MARIE-CLAIRE GUBLER, ANNE-LISE DELEZOIDE, FRANÇOISE MULLER, \\ PATRICK MADELENAT, NICHOLAS M. FISK, AND MARC DOMMERGUES
}

\begin{abstract}
Departments of Obstetrics [D.M.-C., P.M.] and Nuclear Medicine [A.M.], Hôpital Bichat-Claude Bernard AP-HP and Université Paris VII, 75018 Paris, France; Department of Foetal Pathology [J.M.], AP-HP and Université Paris V, Hôpital Necker, 75015 Paris, France; Department of Nephrology and INSERM U423 [M.-C.G.], Hôpital Necker AP-HP, 75015 Paris, France; Department of Foetal Pathology [A.-L.D.], Hôpital Robert Debré, AP-HP and Université Paris VII, 75935 Paris Cedex 19, France; Department of Biochemistry [F.M.], Hôpital Robert Debré, AP-HP and Université Paris Ile de France Ouest, 75935 Paris Cedex 19, France; Imperial College and Queen Charlotte Hospital [N.M.F.], W12 OHS, London, UK; and Maternité Hôpital Necker [M.D.], AP-HP and Université Paris V, 75015 Paris, France
\end{abstract}

\section{ABSTRACT}

RAS down-regulation, the recipient is exposed to RAS effectors elaborated in the donor and transferred via placental shunts. This may contribute to cardiomyopathy and hypertension in the recipient, which cannot be accounted for by hypervolemia alone. We thus hypothesized that in TTTS, the recipient's hypertensive cardiomyopathy could be due to a mechanism similar to the classical model of hypertension referred to as " 2 kidneys- 1 clip." Thus the hypovolemic donor twin, comparable to the clipped kidney, produces vasoactive hormones that compromise the recipient, comparable to the normal kidney, causing hypertension and cardiomyopathy. (Pediatr Res 58: 685-688, 2005)

\author{
Ang II, angiotensin II \\ RAS, renin-angiotensin system \\ TTTS, twin-to-twin transfusion syndrome
}

Abbreviations
Twin-to-twin transfusion syndrome (TTTS) is a severe disease that complicates $15 \%$ of monochorionic twin pregnancies. Despite advances in perinatal management, TTTS still carries a high risk for both fetal and neonatal mortality and morbidity (1-3). It leads to widespread renovascular manifestations in the donor twin, such as oliguria and oligohydramnios, and in the

Received March 16, 2004; accepted January 19, 2005.

Correspondence: Dominique Mahieu-Caputo, M.D., Maternité, Hôpital Bichat, 56 rue Henri Huchard, 75018 Paris, France; e-mail: dominique.mahieu-caputo@bch. ap-hop-paris.fr

DOI: 10.1203/01.PDR.0000180558.03164.E8 recipient to polyuria, polyhydramnios, and occasionally, systemic hypertension, heart failure, and hydrops. Although TTTS certainly originates in unbalanced blood flow through placental anastomoses (4-6), the detailed mechanism that leads to its complex fetal cardiovascular (7-10) and renal disturbances remains unclear. In particular, hypervolemia alone does not account for myocardial hypertrophy in the recipient, which can be severe enough to result in obstructive valvular lesions $(7,9)$. Hypervolemia alone also fails to explain profound vascular disturbances in the recipient fetus, such as systemic hypertension, as suggested by postmortem findings (11) and recently documented in vivo by Doppler studies (10). Furthermore, the 
severity of the syndrome does not always correlate with intertwin differences in $\mathrm{Hb}$ concentrations, and severe cardiomyopathy may occur in cases in which the recipient and the donor have similar hematocrits $(12,13)$. Finally, intertwin transfer of blood or water cannot explain intractable polyhydramnios in the recipient $(10,14,15)$.

We previously hypothesized that discordant renin angiotensin system (RAS) activation could be the link between abnormalities in fetal blood volume and vascular disturbances in TTTS. We first demonstrated that renal expression of renin was up-regulated in donors and down-regulated in recipient twins (11). This phenomenon, since confirmed by others (16), could be interpreted initially as a physiologic adaptation to hypovolemia in the donor and hypervolemia in the recipient. However, we have speculated that this adaptation then could go on to become deleterious, particularly to the recipient, who could be exposed to the transfer of a variety of molecules produced by the donor via intertwin vascular anastomoses, including vasoactive RAS hormones (15). The RAS plays a major role in maintaining vascular tone, optimal salt and water homeostasis, and cardiac function in humans. Its overreactivity, however, has been recognized to result in conditions such as hypertension, renal artery stenosis, left ventricular hypertrophy, and congestive heart failure (17). We report a case in which stage IV TTTS resulted in preterm delivery and immediate neonatal death of both twins, allowing simultaneous assessment of the RAS status of each fetus by both venous cord blood renin and aldosterone assays and by renal immunohistochemistry.

\section{CASE REPORT}

A 30-y-old para 1 gravida 3 was referred at 24 wk for acute polyhydramnios in a twin pregnancy. Monochorionic diamniotic placentation had been documented by first-trimester ultrasound. No other sonographic examination had been done since then. The diagnosis of TTTS was made on the basis of gross discordance in amniotic fluid volume, with severe polyhydramnios in one twin (deepest pool $10 \mathrm{~cm}$ ) and severe oligohydramnios in the other (deepest pool $1 \mathrm{~cm}$ ). The polyhydramniotic recipient had hypertrophic dilated cardiomyopathy with tricuspid and mitral regurgitation and mild ascites but with normal arterial umbilical blood flow and no s.c. edema. Abdominal and cephalic circumferences corresponded to the 90th centile, whereas femoral length corresponded to the 50th centile for gestational age. The oligohydramniotic donor had a small bladder, $\leq 8 \mathrm{~mm}$ in diameter, and normal arterial umbilical blood flow. Abdominal, cephalic, and femoral measurements ranged between the 40th and 60th centiles. TTTS was considered as severe since the donor was stuck and the recipient had heart failure. An amnioreduction of $2 \mathrm{~L}$ was performed, followed by spontaneous premature rupture of membranes and labor. The infants weighed 750 and $610 \mathrm{~g}$, respectively, and died immediately after vaginal delivery. No attempt at resuscitation was made. Postmortem examination confirmed monochorionic placentation and absent associated malformations. The recipient had ascites and hepatomegaly. His heart was enlarged with moderate myocardial hypertrophy. The recipient's and donor's kidneys weighed 655 and $560 \mathrm{~g}$, respectively.
For immunohistochemistry, both kidneys of each twin were fixed in $10 \%$ buffered formalin, and frontal corticomedullary sections were taken. Four-millimeter-thick sections were stained with trichrome-light green, trichrome-safran, or periodic acid-Schiff. Immunostaining was performed on formalinfixed, paraffin-embedded tissues using a rabbit anti-renin antibody (provided by P. Corvol, INSERM U36, Paris, France) labeled by avidin-biotin binding and the Universal Immunostaining Streptavidin-Peroxidase Kit (Immunotech, Marseille, France). Sections were counterstained with hematoxylin and mounted in aqueous media. Control sections were processed as above but omitting primary antibody. Semiquantitative evaluation of renin content was performed on strict corticomedullary sections, as previously described (11).

In the donor, most proximal tubes appeared dysgenetic (Fig. 1). In the recipient, the kidneys were congested. Hemorrhagic infarction was present, and glomeruli were enlarged and congestive.

Immunolabeling with anti-renin antibodies showed reninpositive juxtaglomerular apparatus in $90 \%$ of glomeruli in the donor but no renin-positive cells in the recipient's kidney. Neonatal arterial blood cord was sampled in both twins and centrifuged, and the supernatant was stored at $-20^{\circ} \mathrm{C}$. The hematocrits of the donor and recipient were 50 and $45 \%$, respectively. Serum renin concentration, assessed by radioimmunometric assay (Renin 3 Generation; Bio-Rad, ScheringCis-Bio, France), was $385 \mathrm{pg} / \mathrm{mL}$ in the donor and $296 \mathrm{pg} / \mathrm{mL}$ in the recipient, the mean $\pm 95 \%$ confidence interval for neonates being $31.43 \pm 27.3 \mathrm{pg} / \mathrm{mL}$ in our institution. Serum aldosterone concentration, measured using a RIA kit (ALDOCTK-2; Schering-Cis-Bio), was $292 \mathrm{pg} / \mathrm{mL}$ in the donor and $248 \mathrm{pg} / \mathrm{mL}$ in the recipient (within normal range) (18).

Written informed consent was obtained before autopsy was performed. No specific institutional review board approval was sought, because standard perinatal management was not altered by the study. Renal immunochemistry was part of the autopsy protocol, performing a cord blood hematocrit is a routine procedure after the birth of TTTS-affected infants, and hormonal assays were performed on the supernatant obtained after cord blood centrifugation for hematocrit.

\section{DISCUSSION}

In the case, we report that arterial neonatal cord blood concentrations of renin and aldosterone were similar in the donor and recipient twin, whereas, on the basis of the renal immunohistochemistry, one would expect discordant levels,
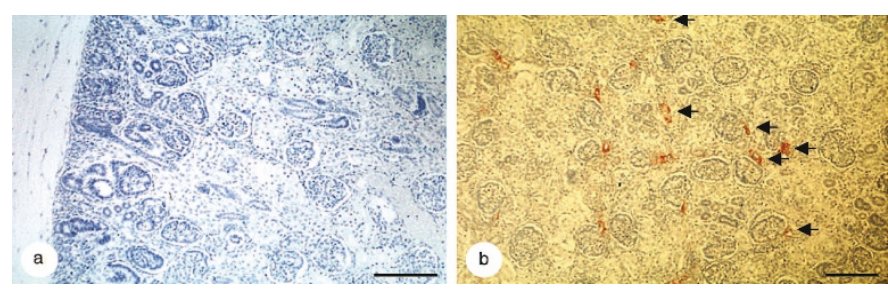

Figure 1. Renin immunolabeling in both twins. (a) In the recipient twin, all juxtaglomerular apparatus are renin negative. (b) In the donor twin, most juxtaglomerular apparatus are renin positive (arrows). Bars $=100 \mu$. 
with particularly low concentrations in the recipient, as a result of RAS down-regulation. That aldosterone and renin were similar in both twins supports the hypothesis that renin and its effectors angiotensin, aldosterone, and maybe other vasoactive hormones produced by the donor kidneys could have passed into the circulation of the recipient by intertwin transfusion along placental vascular anastomoses. This paradoxic extrarenal RAS activation would fit with a global pathophysiologic mechanism for TTTS. Thus, the initiating event would be hypovolemia in the donor and hypervolemia in the recipient resulting from unbalanced intertwin transfusion via placental vascular anastomoses $(6,19)$. Changes in fetal blood volume then would trigger the RAS, which is functional early in pregnancy (19).

In the donor, initial volume depletion would activate the renin-angiotensin cascade, resulting in production of angiotensin II (Ang II), a vasoconstrictor peptide that contributes to maintenance of peripheral blood pressure (20). The beneficial effects of RAS up-regulation are restoration of extracellular volume through stimulation of aldosterone release and maintenance of peripheral blood pressure through the direct action of Ang II on vascular smooth muscle cells (20). These responses, however, would eventually become deleterious to the donor, with Ang II-induced intrarenal vasoconstriction reducing renal blood flow and fetal urine output, which would worsen oligohydramnios. This would also account for the renal tubular dysgenesis pattern observed in donor kidneys at necropsy $(11,21-23)$. By a similar mechanism, fetal RAS upregulation could increase arterial resistance in the donor's placental territory, thereby impairing placental function and contributing to intrauterine growth restriction and decreased arterial diastolic umbilical flow (24). This would also account for long-term arterial remodeling, a phenomenon related to expression of the Ang II receptor and to RAS vasoactive hormones $(25,26)$, which has been documented in donor twins and seems to be preventable through cessation of intertwin transfusion by laser ablation of anastomoses $(26,27)$.

In the recipient, down-regulation of the RAS is expected to increase diuresis, as an adaptation to hypervolemia. This would tend to equilibrate discordant fluid balance but cannot account for the cardiovascular disturbances observed in recipients. Such disturbances, however, are reminiscent of the combined effect of RAS effectors and hypervolemia (28). Indeed, the recipient's rapidly progressive hypertrophic cardiomyopathy $(7,8)$ has been shown to be associated with fetal and neonatal hypertension (10). Increased levels of RAS vasoactive hormones transferred from the donor could well explain this phenomenon. This is supported by the abnormally high levels of renin in the donor and the recipient, in whom a low level of renin was expected, as a result of down-regulation of the RAS. A transfer of renin and/or other RAS effectors from donor to recipient could explain this paradoxically high level of renin in the recipient. That aldosterone was similar in the recipient and in the donor is consistent with the concept of a paradoxic activation of the RAS, but that aldosterone remained within normal range suggests that aldosterone is not likely to be the key RAS effector involved in the pathophysiology of the TTTS. The normality of aldosterone levels despite RAS acti- vation could be accounted for by the complex regulation of the secretion of this hormone. In addition to the RAS, adrenal corticotrophin hormone and the concentrations of potassium and sodium are involved in the regulation of aldosterone production. Besides, the impact of renin on aldosterone secretion is modulated by volemia and sodium concentration. This could explain why aldosterone may remain within normal range even though the RAS is up-regulated. One could hypothesize that the impact of RAS up-regulation on aldosterone secretion would be counterbalanced in the recipient by hypervolemia and in both twins by the absence of sodium depletion because fetal serum concentration of sodium equals that of the mother.

In the case that we report, that the donor had a slightly higher hematocrit than the recipient brings into question the possibility of an acute reversal of blood flow. Should this explain a near intertwin equilibration of renin concentration, it would not alter the conclusions dramatically, because there still would be a paradoxically high serum renin in a recipient in which the production of renin is down-regulated.

RAS effectors are not the sole hormones potentially implicated in the mechanism of TTTS. For instance, increased diuresis and polyhydramnios in the recipient may result in part from the intrarenal effect of RAS down-regulation, but increased volemia and the action of the atrial natriuretic factor (29) are likely to contribute substantially to that phenomenon. Raised endothelin levels, 2- to 3-fold higher in the recipient than in the donor (30), may also contribute, possibly synergistically, through an angiotensin-mediated pathway $(30,31)$.

Our hypothesis may explain how amnioreduction (32) reverses the course of the disease in $\sim 20 \%$ of cases. Amnioreduction, by reducing intra-amniotic pressure (33), improves uteroplacental perfusion (32) and thus presumably also perfusion in the umbilical vein and eventually the renal arteries of the donor, inducing a resumption of urine output (34). Because of the frequency of velamentous insertion (22), the donor's umbilical cord is likely to be particularly susceptible to changes in pressure. In the donor, improved renal perfusion associated with intrarenal RAS down-regulation could explain its restoration of urine output (34). At the same time, a reduction in circulating RAS effectors in the recipient would tend to normalize its cardiovascular changes. The resultant restoration of renin synthesis in the recipient could contribute to decreased polyuria, a phenomenon occasionally observed after amnioreduction.

TTTS therefore emerges as a unique model in which a potentially beneficial adaptation in one twin, i.e. RAS upregulation in the donor, may be deleterious in the co-twin, inducing hypertension and heart failure. TTTS seems to be similar to the classic model of hypertension referred to as " 2 kidneys-1 clip" (35). In the donor (comparable to the clipped kidney), hypoperfusion reduces renal perfusion pressure, upregulating the RAS. The recipient (comparable to the unclipped kidney) is exposed, via placental anastomoses, to RAS effectors such as Ang II and aldosterone, inducing sodium retention and hypertension (Fig. 2). RAS effector intoxication of the recipient would limit the efficacy of polyuria to decrease 


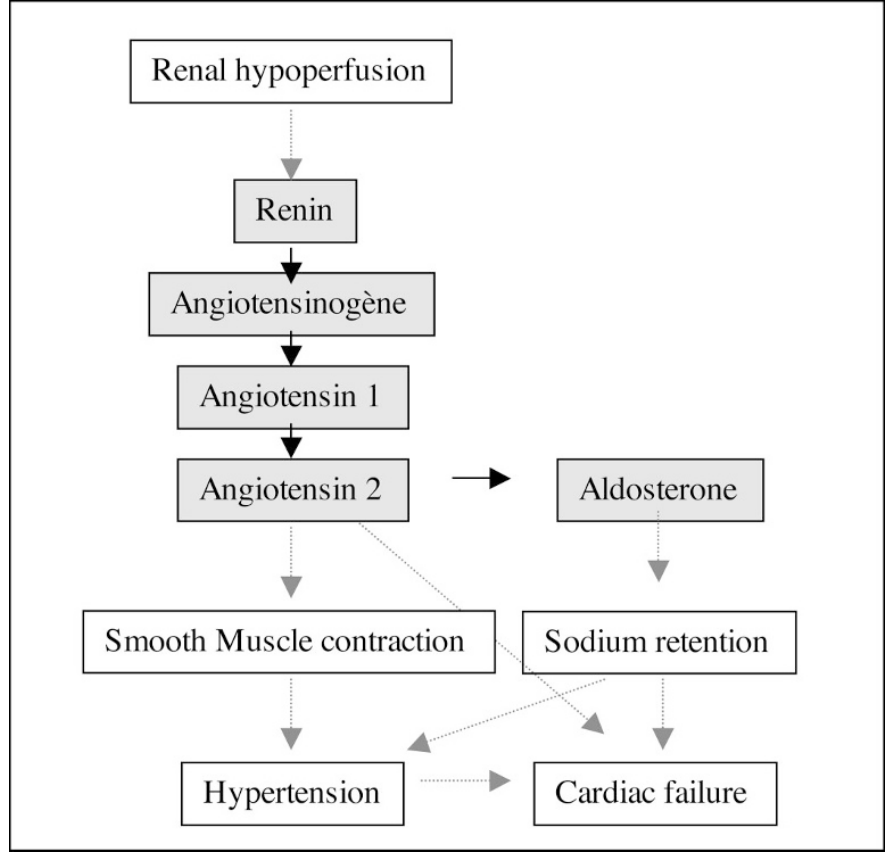

Figure 2. "Two kidneys, one clip" model.

the donor's volemia, eventually resulting in malignant hypertension and congestive heart failure.

Acknowledgments. We thank D. Bonnet, M.D, Ph.D. (cardiologist, Hôpital Necker); L. Fermont, M.D. (cardiologist, Institut de puériculture); J. Lebidois, M.D. (cardiologist, Hôpital Necker); and J. Menard, M.D., Ph.D. (Faculté de Médecine Paris VI), for helpful discussions on the pathophysiology of TTTS.

\section{REFERENCES}

1. Ville Y, Hecher K, Gagnon A, Sebire N, Nicolaides K 1998 Endoscopic laser coagulation in the management of severe twin-twin transfusion syndrome. Br J Obstet Gynaecol 105:446-453

2. Hecher K, Plath H, Bregenzer T, Hansmann M, Hackeloer BJ 1999 Endoscopic laser surgery versus serial amniocentesis in the treatment of twin-twin transfusion syndrome. Am J Obstet Gynecol 180:717-724

3. Gaziano EP, De Lia JE, Kuhlmann RS 2000 Diamnionic monochorionic twin gestations: an overview. J Matern Fetal Med 9:89-96

4. Bajoria R, Wigglesworth J, Fisk NM 1995 Angioarchitecture of monochorionic placentas in relation to the twin-twin transfusion syndrome. Am J Obstet Gynecol 172:856-863

5. Machin G, Still K, Lalani T 1996 Correlations of placental vascular anatomy and clinical outcomes in 69 monochorionic twin pregnancies. Am J Med Genet 61:229236

6. Denbow ML, Cox P, Taylor M, Hammal DM, Fisk NM 2000 Placental angioarchitecture in monochorionic twin pregnancies: relationship to fetal growth, fetofetal transfusion syndrome, and pregnancy outcome. Am J Obstet Gynecol 182:417-426

7. Zosmer N, Bajoria R, Weiner E, Rigby M, Vaughan J, Fisk NM 1994 Clinical and echographic features of in utero cardiac dysfunction in the recipient twin in twin-twin transfusion syndrome. Br Heart J 72:74-79

8. Fesslova V, Villa L, Nava S, Mosca F, Nicolini U 1998 Fetal and neonatal echocardiographic findings in twin-twin transfusion syndrome. Am J Obstet Gynecol 179:1056-1062
9. Karatza AA, Wolfenden JL, Taylor MJ, Wee L, Fisk NM, Gardiner HM 2002 Influence of twin-twin transfusion syndrome on fetal cardiovascular structure and function: prospective case-control study of 136 monochorionic twin pregnancies. Heart 88:271-277

10. Mahieu-Caputo D, Salomon LJ, Le Bidois J, Fermont L, Brunhes A, Jouvet P, Dumez Y, Dommergues M 2003 Fetal hypertension: an insight into the pathogenesis of the twin-twin transfusion syndrome. Prenat Diagn 23:640-645

11. Mahieu-Caputo D, Dommergues M, Delezoide AL, Lacoste M, Cai Y, Narcy F, Jolly D, Gonzales M, Dumez Y, Gubler MC 2000 Twin-to-twin transfusion syndrome. Role of the fetal renin-angiotensin system. Am J Pathol 156:629-636

12. Saunders NJ, Snijders RJ, Nicolaides KH 1991 Twin-twin transfusion syndrome during the 2nd trimester is associated with small intertwin hemoglobin differences. Fetal Diagn Ther 6:34-36

13. Denbow M, Fogliani R, Kyle P, Letsky E, Nicolini U, Fisk N 1998 Haematological indices at fetal blood sampling in monochorionic pregnancies complicated by fetofetal transfusion syndrome. Prenat Diagn 18:941-946

14. Brace R 1989 Fetal blood volume, urine flow, swallowing, and amniotic fluid volume responses to long-term intravascular infusions of saline. Am J Obstet Gynecol 161:1049-1054

15. Mahieu-Caputo D, Muller F, Joly D, Gubler MC, Lebidois J, Fermont L, Dumez Y, Dommergues M 2001 Pathogenesis of twin-twin transfusion syndrome: the reninangiotensin system hypothesis. Fetal Diagn Ther 16:241-244

16. Kilby MD, Platt C, Whittle MJ, Oxley J, Lindop GB 2001 Renin gene expression in fetal kidneys of pregnancies complicated by twin-twin transfusion syndrome. Pediatr Dev Pathol 4:175-179

17. Brewster UC, Setaro JF, Perazella MA 2003 The renin-angiotensin-aldosterone system: cardiorenal effects and implications for renal and cardiovascular disease states. Am J Med Sci 326:15-24

18. Sparano F, Sciarra F, Natoli G, Mercuri MA, Odoardi A, Colangelo E 1978 Behaviour of plasma renin activity and aldosterone during the first $72 \mathrm{~h}$ of life. Clin Endocrinol (Oxf) 8:207-211

19. Talbert DG, Bajoria R, Sepulveda W, Bower S, Fisk NM 1996 Hydrostatic and osmotic pressure gradients produce manifestations of fetofetal transfusion syndrome in a computerized model of monochorial twin pregnancy. Am J Obstet Gynecol 174:598-608

20. Gomez RA, El-Dahr S, Chevalier RL 1999 In: Barratt TM Avner ED Harmon WE (eds) Pediatric Nephrology, Vasoactive Hormones, 4th Ed. Lippincott Williams \& Wilkins, London, pp 83-99

21. Gubler MC, Sarrut S, Imbert MC, Narcy F, Lacoste M, Guicharnaud L, Gasc JM, Mounier F 1993 Renal tubular dysgenesis (RTD), an autosomal recessive disorder and the renin-angiotensin system. J Am Soc Nephrol 4:263

22. Machin GA 1997 Velamentous cord insertion in monochorionic twin gestation. An added risk factor. J Reprod Med 42:785-789

23. Barr M Jr, Sedman AB, Heidelberger KP 1998 Renal tubular dysgenesis in twins Pediatr Nephrol 12:408-413

24. Hecher K, Ville Y, Nicolaides KH 1995 Fetal arterial Doppler studies in twin-twin transfusion syndrome. J Ultrasound Med 14:101-108

25. Ratajska A, Campbell SE, Cleutjens JP, Weber KT 1994 Angiotensin II and structural remodeling of coronary vessels in rats. J Lab Clin Med 124:408-415

26. Cheung YF, Taylor MJ, Fisk NM, Redington AN, Gardiner HM 2000 Fetal origins of reduced arterial distensibility in the donor twin in twin-twin transfusion syndrome. Lancet 355:1157-1158

27. Gardiner HM, Taylor MJ, Karatza A, Vanderheyden T, Huber A, Greenwald SE, Fisk NM, Hecher K 2003 Twin-twin transfusion syndrome: the influence of intrauterine laser photocoagulation on arterial distensibility in childhood. Circulation 107:19061911

28. Baker KM, Booz GW, Dostal DE 1992 Cardiac actions of angiotensin II: Role of an intracardiac renin-angiotensin system. Annu Rev Physiol 54:227-241

29. Wieacker P, Wilhelm C, Prompeler H, Petersen KG, Schillinger H, Breckwoldt M 1992 Pathophysiology of polyhydramnios in twin transfusion syndrome. Fetal Diagn Ther 7:87-92

30. Bajoria R, Sullivan M, Fisk NM 1999 Endothelin concentrations in monochorionic twins with severe twin-twin transfusion syndrome. Hum Reprod 14:1614-1618

31. Kanno K, Hirata Y, Tsujino M, Imai T, Shichiri M, Ito H, Marumo F 1993 Up-regulation of ETB receptor subtype mRNA by angiotensin II in rat cardiomyocytes. Biochem Biophys Res Commun 194:1282-1287

32. Bower SJ, Flack NJ, Sepulveda W, Talbert DG, Fisk NM 1995 Uterine artery blood flow response to correction of amniotic fluid volume. Am J Obstet Gynecol 173:502 507

33. Fisk NM, Borrell A, Hubinont C, Tannirandorn Y, Nicolini U, Rodeck CH 1990 Fetofetal transfusion syndrome: do the neonatal criteria apply in utero? Arch Dis Child 65:657-661

34. Umur A, van Gemert MJ, Ross MG 2001 Fetal urine and amniotic fluid in monochorionic twins with twin-twin transfusion syndrome: simulations of therapy. Am J Obstet Gynecol 185:996-1003

35. Wood JM, Gulati N, Michel JB, Hofbauer KG 1986 Two-kidney, one clip renal hypertension in the marmoset. J Hypertens 4:251-254 